scien do Zagreb International Review of Economics \& Business, Vol. 22, Special Conference Issue, pp. 69-82, 2019 (C) 2019 Faculty of Economics and Business, University of Zagreb and De Gruyter Open All rights reserved. Printed in Croatia ISSN 1331-5609; UDC: $33+65$

DOI: 10.2478 /zireb-2019-0005 CONFERENCE PAPER

\title{
Quality of Government and Well-being: Assessing the Gap in European Countries
}

\author{
Oana Ramona Lobont* \\ Sorana Vatavu** \\ Oana Ramona Glont*** \\ Lavinia Daniela Mihit ${ }^{* * *}$
}

\begin{abstract}
This paper analyses the influential factors which determine the differences between social and economic dimensions in the European Union. The main objective was to construct a composite indicator of the quality of government and citizens' well-being, and rank the EU countries based on it. The dataset refers to variables specific to economic and social wellness (latest year available is 2015), focusing on both, the objective and subjective dimension of the governance and well-being. The results obtained indicate that the countries with the highest performance in terms of the quality of government and citizens'well-being are Denmark, Sweden, Finland, followed by Austria and the Netherlands. Differences to the rest of the EU member states are based on economic and social policies, as these countries have the highest employment rates and social protection expenditures, focusing on the risks related to unemployment, social exclusion, invalidity or aging to increase citizens' overall life satisfaction.
\end{abstract}

Keywords: quality of government; well-being; composite indicators; EU

JEL Classification: E02, I31, C43

\footnotetext{
${ }^{*}$ Oana Ramona Lobont, Assoc. Prof., Ph.D., Faculty of Economics and Business Administration, West University of Timisoara, Romania

${ }^{* *}$ Sorana Vatavu, Lect., Ph.D., Postdoctoral Researcher, Faculty of Economics and Business Administration, West University of Timisoara, Romania

*** Oana Ramona Glont, Lavinia Daniela Mihit, Ph.D. Stud., Doctoral School of Economics and Business Administration, West University of Timisoara, Romania.
} 


\section{Introduction}

In terms of social and economic development, there are some differences within the European Union (EU). Several possible explanations were offered over time, ranging from macroeconomic policy conditions to the cultural exodus phenomenon within the Member States. A further explanation would be related to the quality of the government, which is not the best in many countries. In general, statistics describe the economic performance through a series of indicators related to Gross Domestic Product (GDP). Although these economic indicators are important, they do not show us a complete picture of the well-being of a society.

The objective of this paper is to identify the main factors influencing the differences between the EU countries, in terms of quality to citizens' well-being through a comparative analysis, using a composite indicator that includes the main components of the social and economic dimensions available for 2015. The paper will present part of the literature related to measuring the "quality of government", and some of the results obtained in previous studies, explaining the variations between the EU Member States.

Another important issue that needs to be addressed is the definition of the "quality of life" of EU citizens. Related to the state development, this dimension is more subjective, involving multilateral analysis. International surveys already identified the most influential factors that determine citizens in one state to form a certain degree of satisfaction related to general life conditions, including the degree of trust in public institutions.

In order to identify and effectively compare the main disparities within the EU, the case study consists in realising a composite index, using the Organisation for Economic Co-operation and Development (OECD) methodology. The purpose of this index is to include several individual variables, related to objective (economic) aspects as well as subjective (social) ones. In this way, the indicator is capable of an overall evaluation of the quality of governance and citizens' well-being in the EU member countries.

The conclusions of the paper summarise important differences in terms of economic and social development in the EU. The variance is due to a lack of government transparency and increased corruption in some countries, affecting citizens' confidence in public institutions and their general well-being. For all the EU member states to be successful in implementing policies and increasing citizens' confidence, governmental reforms should consider the Scandinavian model, as this is the most efficient in terms of both, government efficiency and quality of life. 


\section{The Concept of the Quality of Government}

Although the quality of governance and citizens' satisfaction at a national and international level has already been debated in the literature, there is no standard definition for the "quality of governance". The governance concept would refer to the institutions through which a state exercises the authority. On one hand, it is about Government's ability to effectively implement the best policies. On the other hand, governance depends on the respect offered by the citizens and the state towards the institutions that regulate the economic and social interactions between them.

Rothstein and Teorell (2008) considered the relationship between high-quality government and democracy, observing whether or not the two are concurrent. Although democracy, which refers to access to state power, is absolutely necessary for measuring the quality of governance, it is insufficient as an exclusive indicator. If the two concepts would be equal, the ways through which power was exercised by the government would be left externally, while the emphasis would be more on the means through which it was obtained. Collier (2007) showed that both notions are essential as long as the international community is focused on promoting democratic means to increase the power in the state, especially in developing countries. It seems that the relationship between democracy and quality of government is a curvilinear one, indicating that democratic states may sometimes be inferior in terms of the quality of government when compared to non-democratic states. Simultaneously, for countries in which the democratic regime has been established for a long time, it is more likely for their citizens to benefit from a higher level of government quality. However, examples of post-communist regimes show that the transition is not a simple, nor a fast process.

Good governance is not necessarily linked to democracy, as some of the most advanced countries, such as Hong Kong or Singapore, significant results for good governance, but they are not democratic. Excluding such examples from the analysis realised in this paper, it can be stated that high-quality governance requires a democratic access to power and impartiality in exercising this power in a state. Therefore, the democracy should be considered as an essential element in the quality of government, but it is far from being the only condition.

Regarding the differences across EU members, states tend to receive a higher score if, first of all, they are perceived as resistant to a government changeover, without experiencing significant interruptions of the daily administrative services. Secondly, if the potential for corruption in the form of abuse of power, nepotism, parties' secret funds, or ties between political parties and business environment, is perceived as a phenomenon that is rarely encountered, countries receive better scores.

In general, political aspects and changes in the political environment are those that differentiate more developed countries. Referring to developing countries, Kaufmann et al. (2009) mentioned that despite the fact that the government corruption seems to be the real challenge for the developing world, this view can be disapproved. The 
general tendency from the empirical analysis shows that, on average, European countries do not have a clear improvement in their level of governance quality over the past two decades. In fact, for many EU countries, the trend is rather negative. Either these levels are due to some measurement errors, or the countries are indeed subject to an important decline in the quality of government, which requires an increased attention from the authorities.

\section{Measuring the Quality of Government and Quality of Life}

According to recent data, most indicators on the quality of government show that, although the average level in the European Union is higher compared to other regions of the world, there are significant discrepancies between member countries. As measuring indicators such as bureaucracy or corruption can often be difficult, there is more debate on the best way to measure the quality of governance. Many researchers have doubts on how the indicators nowadays can present valid measures for certain governance concepts such as "corruption", "rule of law" or "bureaucratic efficiency". Therefore, any measures undertaken will not be able to capture all the government aspects. However, researchers in comparative policy and economic development agreed on the fact that the quality of government is a broad concept, and it needs to be disaggregated into several categories. Kaufmann et al. (2009) listed them into six governance dimensions: i) control of corruption; ii) government effectiveness; iii) rule of law; iv) regulatory quality; v) political stability and absence of violence and terrorism; vi) voice and accountability, expressing the democratic power of the electoral authorities. Besides the quality of government, these aspects also measure the public sector performance, and allow a meaningful comparison across the EU countries, at the national level. Based on the aspects previously listed and aggregated into one index, every country can now be described by the Worldwide Governance Indicators (WGl).

Following the study on WGI, the Quality of Government Institute of Gothenburg University from Sweden realised a report for the European Commission on the quality of governance in the EU. In this study, a new index at the EU level was developed, entitled the European Quality of Government Index (EQI). The construction of this index was realised through a database obtained from a survey involving approximately $34,000 \mathrm{EU}$ citizens, is the largest study ever conducted to measure the quality of governance at national and regional level.

A brief examination of the variance in the EQI index at a regional level is illustrated in Figure 1, and it reveals fairly predictable models regarding the quality of government among the regions. All regions from the best performing EU Member States - Denmark, Sweden, the Netherlands - are in the first $15 \%$ of the total. 
Figure 1: EQI at inter-regional level. Standard deviation and interval from inferior (negative) to superior (positive) quality

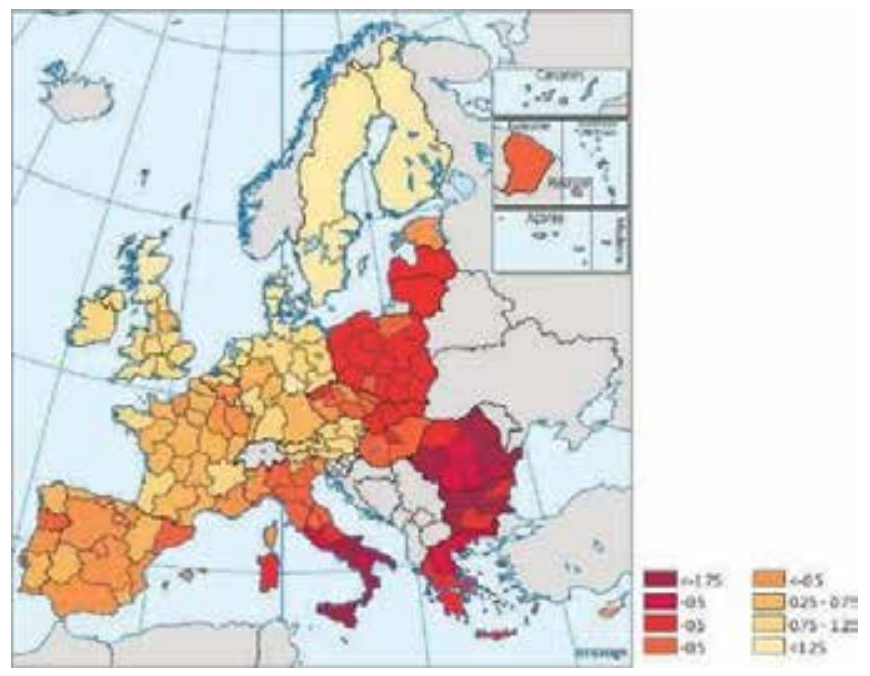

Source: data.worldbank.org

From the new member states, all except one are in the lower rank of 50\%, registering a negative score. The northwestern side of Romania is the exception, with a score of $0.21 \%$. Most regions of the first $15 \mathrm{EU}$ countries are in top 50\%, except Portugal and Greece which have all regions classified under the average. Moreover, a few regions from France and Italy are listed below the EU average, under the last $10 \%$. The data shows variations from one region to another at the national level. Applying the error margins (95\%) to the regional estimated values, we find that some countries display very similar interregional results groups, while others record differences in the quality of government within the respective regions, and these differences are statistically significant. Table 1 presents a restructuring of EU countries in terms of the variations in the regional level.

Table 1: The level of internal variations in the EU member states

\begin{tabular}{|l|l|l|}
\hline \multicolumn{1}{|c|}{ High } & \multicolumn{1}{c|}{ Low } \\
\hline Belgium & Czech Republic & Denmark \\
\hline Spain & Germany & Netherlands \\
\hline Italy & France & Sweden \\
\hline Portugal & Greece & Poland \\
\hline Romania & United Kingdom & Slovakia \\
\hline Bulgaria & Hungary & Austria \\
\hline
\end{tabular}

Source: data.worldbank.org 
From these results, several interesting conclusions can be drawn. One of them is that the number of regions in a country is not an indicator to predict inter-regional variations. For example, while Denmark and Slovakia have only four or five regions, Poland, with 16 regions, shows the same variation within the country. On the other hand, Belgium and Portugal, with only three and six regions, show relatively large discrepancies in the quality of government from one region to another. France, with the largest number of regions in the analysis, presents only moderate variation inside the country.

It was also revealed that a federal administration system or a very centralized system does not assume a reliable indication of predicting the precise level of regional variation. For example, federal countries such as Germany and Austria, present a moderate to low level of variation, while other federal / semi-federal provinces such as Italy, Belgium, and Spain have a significantly high degree. Slovakia and Netherlands are countries with a centralized administration system, showing a low variation within the country, while Romania or Bulgaria demonstrates high levels of variations, even though most of the regions within them are in the last $15 \%$ between the survey results. This demonstrates that variations in the quality of government can be closely linked to political or administrative choices (e.g. Italy, Belgium, Spain), but also to how well-distributed is the workforce. The latter also affects more centralized countries.

Lastly, the fact that the country analysed is a founding member or a new member of the EU can not predict regional variations. Results show that the highest variance is in both categories, the first 15 EU Member States, including two of the founding states, but also in two new member countries.

The "quality of life" is a broader concept than the level of economic development, including a range of factors that influence what citizens care for, beyond the material aspects. Therefore, this concept is multidimensional, comprising a set of indicators. Within this framework, indicators can be statistically measured in order to present complementary aspects of quality of life, and at the same time complement the GDP, which is the traditional indicator of economic and social development.

Eight of the factors referred to citizens' capacity to reach a certain level of well-being, according to own standards, values, and priorities. These are material living standards, employment, education, health, leisure and social interactions, economic and physical safety, governance and human rights, living environment. There is a ninth factor, the overall life satisfaction, referring to the personal perception of life quality, related to the individual life scope.

In 2013, Eurostat introduced a model regarding the subjective well-being, using statistics related to income and life conditions. This presents a set of variables with personal opinions on life in general, but several dimensions of life quality to which data on income to the conditions of life were added. These are often used in the con- 
text of assessing the poverty and social exclusion. The perception of the citizens on the quality of life represents the concept of "subjective well-being", and thus, for the first time, the quality of life in the EU was assessed, respecting the quality standards for official statistics in terms of objectivity and subjectivity. This data was analysed along with other factors affecting the quality of life, such as education and health level, or financial and family situations.

This study illustrates the need to analyse more into depth the macroeconomic indicators, to monitor both, economic and social progress. Considering that an exclusive analysis of GDP would lead to different results and conclusions, this analysis will relate to additional indicators of welfare and governance.

\section{Data and Methodology}

According to the OECD methodology on developing composite indicators, the theoretical framework provides a basis for selecting and combining the variables into a significant composite indicator, useful in providing the desired information. In order to measure the quality of governance and citizens well-being, and compare it across the EU, a composite index will be computed in order to offer us a clear picture on the discrepancies between the states.

Two dimensions will be integrated into this index: the objective dimension related to the economic aspects, and the subjective dimension, related to social aspects. The economic dimension will include the following three ratios:

- Employment rate (\% of GDP) - this indicator is computed by dividing the number of employees between 20 and 64 years, in relation to the total population of the same age group, and it is based on the EU Labor Force Survey. The employed population is made up of individuals who, during the reference week, realised paid activities for at least one hour, or did not work at the moment but were officially employed.

- Public Investment Ratio (\% of GDP) - this indicator is defined as the gross capital formation, expressed as a percentage of GDP, to be invested in the public, private and household sectors. This report indicates the share of GDP used for the gross investment.

- Social Protection Expenditure Ratio (\% of GDP) - social protection expenditures refer to social benefits, which consist of cash or in-kind transfers to individuals and households, in order to reduce or eliminate the burden of the risks and needs. This indicator also refers to the costs of public administration system and other expenses, consisting of various expenses of the social protection systems. 
The social dimension comprises two indicators:

- Confidence in EU Institutions (\% of the population) - is expressed as a share of positive opinions offered by those who say they tend to trust the European Union institutions (the Council of the European Union, European Parliament, and European Commission). This indicator is based on the "Eurobarometer", a survey conducted twice a year, since 1973, to observe public awareness in the Member States. Regarding the answers possible to the question regarding the level of trust ("I trust", "I do not trust" or "I do not know") and the fact that trust is not accurately defined, leaves room for personal interpretations for those interviewed.

- Quality of Life (\% of the population) - is the way in which a person evaluates or appreciates life as a whole. This indicator is intended to express a broad and more reflective assessment by interviewees. It is not intended to present the emotional state of the respondents, but a reflective judgment on the level of general satisfaction of life (financial situation, housing, workplace, living environment, leisure and social life). The indicator reflects the percentage of respondents who showed a high level of life satisfaction.

All the indicators used in this analysis are from 2015, referring to every EU member state. The source of data was Eurostat, providing information on the public investment ratio, social protection expenditure ratio, employment rate, confidence in EU institutions, and quality of life.

The multivariate analysis using the Principal Component Analysis (PCA) is a statistical method that converts of a set of correlated variables into a set of linear and uncorrelated variables. The new set is known as principal components and may be consisting of less or the same number of variables. Under this transformation a set of components is obtained: the first major component has the largest variance possible, with successive components having smaller variances. PCA objective is to explain the variance in a dataset, using linear combinations between the original data. The first step is to analyze how closely related the selected indicators are, in order to realise the composite index. For this, we start by analysing the correlation coefficients between the variables. Then, we observe the principal components corresponding to the number of indicators, and select the first components that retain a significant amount of the cumulative variance in the original data.

Even though the analysis considers " $n$ " variables (in this case there will be five), $\mathrm{x}_{1}, \mathrm{x}_{2}, \ldots, \mathrm{x}_{\mathrm{n}}$, a large amount of the data variation can be determined by a small number of the principal components, noted $\mathrm{Z}_{1}, \mathrm{Z}_{2}, \ldots, \mathrm{Z}_{\mathrm{n}}$, and computed as presented in the equations below:

$$
\begin{aligned}
& \mathrm{Z}_{1}=\mathrm{a}_{11} \mathrm{x}_{1}+\mathrm{a}_{12} \mathrm{x}_{2}+\ldots+\mathrm{a}_{1 \mathrm{n}} \mathrm{x}_{\mathrm{n}} \\
& \mathrm{Z}_{2}=\mathrm{a}_{21} \mathrm{x}_{1}+\mathrm{a}_{22} \mathrm{x}_{2}+\ldots+\mathrm{a}_{2 \mathrm{n}} \mathrm{x}_{\mathrm{n}} \\
& \ldots \ldots \ldots \\
& \mathrm{Z}_{\mathrm{n}}=\mathrm{a}_{\mathrm{n} 1} \mathrm{x}_{1}+\mathrm{a}_{\mathrm{n} 2} \mathrm{x}_{2}+\ldots+\mathrm{a}_{\mathrm{nn}} \mathrm{x}_{\mathrm{n}}
\end{aligned}
$$


The weights, $\mathrm{a}_{\mathrm{ij}}$, known as component loadings, that apply to $\mathrm{x}_{\mathrm{j}}$ variables, are chosen so that the main components, $\mathrm{Z}_{\mathrm{i}}$, have fulfilled the following conditions: $\mathrm{i}$ ) they should not be correlated; ii) the first and main component includes the maximum amount of the variation in the dataset, the second component is the inclusion of the maximum variation remained until the last of the main components absorbs the remaining variance that is not embedded by the previous components.

\section{Results}

Table 2 includes the correlations between the variables used in the analysis. We observe that the indicators show positive and negative correlations, with the highest coefficients for the direct relationships between employment rate and quality of life, and public investment ratio and confidence in EU institutions (correlation coefficients of 0.52 , and 0.51 respectively). From now on, the abbreviations used for the variables will be the following: Employment Rate - Empl.; Public Investment Ratio - Publ. Invest.; Social Protection Expenditure Ratio - Soc.Prot.Exp.; Confidence in EU Institutions - Confid.; Quality of Life - QoL.

Table 2: Correlation matrix between variables

\begin{tabular}{|l|c|c|c|c|c|}
\hline & Empl. & Publ.Invest. & Soc.Prot.Exp. & Confid. & QoL \\
\hline Empl. & 1 & 0.38 & 0.14 & 0.35 & 0.52 \\
\hline Publ.Invest. & & 1 & -0.31 & 0.51 & 0.19 \\
\hline Soc.Prot.Exp. & & & 1 & -0.21 & 0.45 \\
\hline Confid. & & & & 1 & 0.35 \\
\hline QoL & & & & & 1 \\
\hline
\end{tabular}

Table 3 includes the loadings of the components for individual indicators. High and average loadings $(>0.50)$ indicate how individual indicators are influenced by the principal components.

Table 3: Loadings of the principal components for individual indicators

\begin{tabular}{|l|c|c|c|c|c|}
\hline \multicolumn{1}{|c|}{ Loadings } & PC(1) & PC(2) & PC(3) & PC(4) & PC(5) \\
\hline Empl. & 0.283 & 0.026 & 0.415 & 0.238 & 0.038 \\
\hline Publ.Invest. & 0.222 & 0.162 & 0.065 & 0.548 & 0.003 \\
\hline Soc.Prot.Exp. & 0.001 & 0.544 & 0.010 & 0.138 & 0.306 \\
\hline Confid. & 0.257 & 0.074 & 0.449 & 0.071 & 0.149 \\
\hline QoL & 0.237 & 0.195 & 0.061 & 0.004 & 0.504 \\
\hline
\end{tabular}

In order to compute the values for the principal components, we will use the equations mentioned above. For example, the value of the first principal component, PC(1), for a country with variables $x_{j}$, would become: 


$$
\mathrm{PC}(1)=0.283 \mathrm{x}_{1}+0.222 \mathrm{x}_{2}+0.001 \mathrm{x}_{3}+0.257 \mathrm{x}_{4}+0.237 \mathrm{x}_{5}
$$

After computing all the values for the principal components for every EU country, the correlation matrix between them showed that all the coefficients are null. Therefore, the principal components are not correlated.

The variance in the principal components is presented in Table 4 . The first principal component has a variation of 2.16 explaining the maximum variation of all individual indicators (43.1\%). The second principal component explains the maximum value of the residual variance, $31 \%$, with a variation of 1.54 . The third component has a value of 0.57 , and the last two main components explain the remaining $14.6 \%$ of the variance in the dataset.

Table 4: The variance of the principal components

\begin{tabular}{|l|c|l|l|l|c|}
\hline & $\mathrm{PC}(1)$ & $\mathrm{PC}(2)$ & $\mathrm{PC}(3)$ & $\mathrm{PC}(4)$ & $\mathrm{PC}(5)$ \\
\hline Variance of principal component (eigen value) & 2.16 & 1.54 & 0.57 & 0.43 & 0.30 \\
\hline \% of the total variance explained by the principal component & $43.1 \%$ & $31 \%$ & $11 \%$ & $9 \%$ & $6 \%$ \\
\hline Cumulative \% of the total variance explained by PC & $43.1 \%$ & $74 \%$ & $85.4 \%$ & $93.9 \%$ & $100 \%$ \\
\hline
\end{tabular}

In order to proceed to the following step in the analysis, we select the principal components that individually include more than $10 \%$ of the total variance, and more than $60 \%$ cumulative (PC1, PC2, and PC3). Altogether, these components explain a significant amount of $85.4 \%$ of the total variations in the dataset.

For the weighted aggregation of the individual indicators, in order to build the Composite Index for Quality of Government and Citizens' Wellbeing (CIQGCW), it is necessary to determine the correlation between each of the main components chosen in the previous step. Therefore, a higher correlation coefficient indicates a more significant contribution of the indicator to total variations. Depending on the contribution to the total variation, it will be possible to apply the weights for every variable in the composite index calculation process. Since there were three principal components selected, CIQGCW will be built on three sub-indicators. They will be calculated based on the correlation coefficients of every individual indicator with three squared sub-indicators. Moreover, due to the fact that the three principal components comprise $85.4 \%$ of the total variance, instead of $100 \%$, the coefficients obtained will be weighted once again depending on the maximum value $(85.4 \%)$, in order to obtain $100 \%$ for the sum of the final weights. This way, the weights of the individual indicators will be translated by multiplying the normalised correlation coefficients of every indicator with the weights of the total variance in the principal components. For example, the weight of the individual indicator Employment rate will be computed as: 


$$
\mathrm{W} 1=0.28 \times 0.51+0.03 \times 0.36+0.42 \times 0.13
$$

Detailed results on the correlation coefficients computed and normalised are presented in Table 5, along with their weights.

Table 5: Correlation coefficients (computed and normalised) and corresponding weights

\begin{tabular}{|c|c|c|c|c|c|c|c|c|c|c|}
\hline $\begin{array}{l}\text { Individual } \\
\text { indicators }\end{array}$ & $\mathrm{PC}(1)$ & $\mathrm{PC}(2)$ & $\mathrm{PC}(3)$ & $\mathrm{PC}(1)$ & $\mathrm{PC}(2)$ & $\mathrm{PC}(3)$ & $\begin{array}{c}\mathrm{PC}(1)^{2} \\
\text { normalised }\end{array}$ & $\begin{array}{c}\mathrm{PC}(2)^{2} \\
\text { normalised }\end{array}$ & $\begin{array}{c}\mathrm{PC}(3)^{2} \\
\text { normalised }\end{array}$ & Weight \\
\hline Empl. & 0.78 & 0.20 & -0.49 & 0.61 & 0.04 & 0.24 & 0.28 & 0.03 & 0.42 & 0.21 \\
\hline Publ.Invest. & 0.69 & -0.50 & -0.19 & 0.48 & 0.25 & 0.04 & 0.22 & 0.16 & 0.07 & 0.18 \\
\hline Soc.Prot.Exp & 0.05 & 0.92 & 0.08 & 0 & 0.84 & 0.01 & 0 & 0.54 & 0.01 & 0.20 \\
\hline Confid. & 0.74 & -0.34 & 0.51 & 0.55 & 0.11 & 0.26 & 0.26 & 0.07 & 0.45 & 0.22 \\
\hline QoL & 0.71 & 0.55 & 0.19 & \begin{tabular}{|l|}
0.51 \\
\end{tabular} & 0.30 & 0.03 & 0.24 & 0.19 & 0.06 & 0.20 \\
\hline $\begin{array}{l}\text { Variance in } \\
\text { principal } \\
\text { component }\end{array}$ & 2.16 & 1.54 & 0.57 & & & & & & & \\
\hline $\begin{array}{l}\text { Weight in } \\
\text { total variance }\end{array}$ & 0.51 & 0.36 & 0.13 & & & & & & & \\
\hline
\end{tabular}

In order to obtain the final composite index (CIQGCW), the additive aggregation linear method will be used. The index for a country "c" will be computed based on the following formula:

$$
C I Q G C W=\sum_{1}^{n} w_{n} I_{n c}
$$

where $\mathrm{w}_{\mathrm{n}}$ is the weight of the individual indicator, and $\mathrm{I}_{\mathrm{nc}}$ represents the value of the indicator in country "c". Based on the results in table 5, we replace the values in the last formula and obtain:

CIQGCW $_{c}=0.21 \times E m p l+0.18 \times$ Publ. Invest. $+0.20 \times$ Soc. Prot. Exp. $+0.22 \times$ Confid. $+0.20 \times Q o L$

The final composite indicators computed for every country in the EU can be observed in Table 6. In order to simplify the further analysis, we grouped the countries in three categories:

- Leaders (CIQGCW $\geq 40$ ) - countries with high degree of development, and a level of quality of government and citizens' well-being above the EU average.

- Potential leaders (CIQGCW between 35 and 39) - countries with a level of quality of government and citizens' well-being around the EU average.

- Dynamic implementers (CIQGCW $\leq 34)$ - countries that have a level of quality of government and citizens' well-being below the European average. 
Table 6: The composite index for Quality of Government and Citizens' Well-being for EU Member States (descending order)

\begin{tabular}{|c|c|c|c|c|c|c|c|}
\hline & Country & Empl. & Publ.Invest. & Soc.Prot.Exp. & Confid. & QoL & CIQGCW \\
\hline \multirow{7}{*}{ 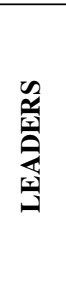 } & 1. Denmark & 76.5 & 19.23 & 32.9 & 59 & 42.7 & 47 \\
\hline & \begin{tabular}{|l|} 
2. Sweden \\
\end{tabular} & 80.5 & 23.65 & 29.6 & 56 & 35.1 & 46 \\
\hline & 3. Finland & 72.9 & 20.46 & 31.9 & 59 & 38.6 & 46 \\
\hline & 4. Austria & 74.3 & 22.61 & 30 & 52 & 37.9 & 44 \\
\hline & 5. Netherlands & 76.4 & 19.43 & 30.9 & 53 & 26.1 & 42 \\
\hline & \begin{tabular}{|l|} 
6. Luxembourg \\
\end{tabular} & 70.9 & 18.98 & 22.7 & 58 & 25.7 & 40 \\
\hline & 7. Germany & 78 & 19.91 & 29.1 & 43 & 25 & 40 \\
\hline \multirow{15}{*}{ 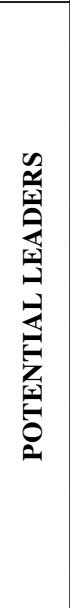 } & 8. Malta & 678 & 25.38 & 18.2 & 58 & 22.5 & 39 \\
\hline & \begin{tabular}{|l|} 
9. Belgium \\
\end{tabular} & 67.2 & 22.99 & 30.3 & 50 & 20.9 & 39 \\
\hline & 10 Poland & 67.8 & 20.07 & 19.1 & 52 & 29.4 & 39 \\
\hline & 11. Lithuania & 73.3 & 1927 & 14.7 & 61 & 18.8 & 39 \\
\hline & 12. Romania & 66 & 24.76 & 14.8 & 60 & 19.7 & 38 \\
\hline & 13. Slovakia & 67.7 & 23.01 & 18.5 & 50 & 25 & 38 \\
\hline & 14. Ireland & 68.7 & 21.2 & 20.6 & 43 & 30.6 & 38 \\
\hline & 15. Czech Republic & 748 & 26.31 & 19.7 & 41 & 21.3 & 37 \\
\hline & 16. France & 69.5 & 21.51 & 34.3 & 38 & 16.1 & 37 \\
\hline & 17. Estonia & 76.5 & 23.65 & $15 . \mathrm{I}$ & 49 & 13.5 & 36 \\
\hline & 18. United Kingdom & 76.8 & 16.93 & 27.4 & 27 & 27.8 & 36 \\
\hline & 19. Hungary & 68.9 & 21.67 & 19.9 & 52 & 11.3 & 36 \\
\hline & 20. Slovenia & 69.1 & 19.51 & 24.1 & 41 & 20.4 & 36 \\
\hline & 21. Latvia & 72.5 & 22.58 & 14.5 & 48 & 12.6 & 35 \\
\hline & \begin{tabular}{|l|} 
22. Portugal \\
\end{tabular} & 69.1 & 15.27 & 26.9 & 44 & 13.8 & 35 \\
\hline \multirow{6}{*}{ 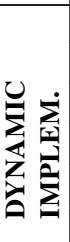 } & 23. Bulgaria & 67.1 & 21.01 & 18.5 & 52 & 5.9 & 34 \\
\hline & 24. Croatia & 606 & 1949 & 21.6 & 45 & 15 & 33 \\
\hline & 25. Italy & 60.5 & 16.81 & 29.9 & 39 & 14.2 & 33 \\
\hline & 26. Spain & 62 & 19.72 & 25.4 & 28 & 18.4 & 31 \\
\hline & \begin{tabular}{|l|} 
27. Cyprus \\
\end{tabular} & 67.9 & 13.31 & 23 & 32 & 14.2 & 31 \\
\hline & 28. Greece & 54.9 & 11.55 & 26 & 32 & 12.8 & 28 \\
\hline
\end{tabular}

These final results indicate that in the Leaders group we have the Scandinavian countries (Denmark, with the highest composite index, followed by Sweden and Finland), together with Austria, the Netherlands, Luxembourg, and Germany. In the Potential Leaders group, we find developed countries such as Belgium or France, as well as emerging ones. Romania is on the $12^{\text {th }}$ place, with an index of 38 , equal with the average at EU level. Dynamic implementers include Bulgaria, Croatia, Italy, Spain, Cyprus, and Greece - with the lowest indicator of 28.

Generally, there should be a direct relationship between employment rate and quality of life, as the population that is part of the labor force market, or is on the improvement stage in terms of education, tends to be more satisfied with the government policies and the EU institutions. This explains why Denmark, Sweden or 
Finland show such high composite index values, as these countries have the highest employment rates in the EU. On the contrary, Greece, with the lowest level of employment rate, shows a low level of quality of life, confidence in government or the EU institutions, which induced the weakest position in the EU ranking.

Another important indicator is the rate of social protection expenditure, reflecting the level of importance granted by every country to this sector. In countries such as Denmark, Finland or Netherlands, this represents more than 30\% of GDP, showing that these countries are investing significant resources in government policy programs in order to reduce poverty and citizens' vulnerability. These policies are implemented through the promotion of efficient labor markets, by reducing the exposure of the population to risks and increasing their capacity to manage social and economic risks, such as unemployment, social exclusion, aging, illness or disability. By adopting such measures, the countries increase the level of confidence of civil society in government institutions, as observed in the process of developing the CIQGCW composite index.

\section{Conclusions}

This paper offers an overview of the issues and gaps in terms of the quality of government and citizens' well-being in the European Union. After measuring and comparing the quality and well-being indicators, we can state the fact that, there are a series of indicators that prevail in quantifying and estimating their dimensions. Among them, there is the level of corruption, public administration efficiency, the level of budget allocations in different sectors, the level of citizens' confidence in the public authorities, etc.

An in-depth analysis is needed in order to define the measurement of the quality of life or its satisfaction, because there is a strong subjective side of the indicator, based on which individuals quantify life satisfaction differently, depending on the social or cultural aspects of every country. The index computed in this paper includes several aspects defined by sociologists (life conditions, health, education, environment, etc.), and they do have a strong impact on the quality of government. Aspects such as the rate of investment in the education system or social protection outline a bi-directional relationship between the economic and social dimension of the well-being. Although the general satisfaction of life depends on several socio-demographic factors (age, income or education) the perception of the quality of life differs as long as citizens have different expectations as individuals.

In order to compare the EU countries using an analytical approach to the issues previously mentioned, we built a composite index of the quality of government and citizens well-being, computed based on data from 2015. Based on this index, we 
identified "leaders", "potential leaders", and "dynamic implementers" between the European countries. Scandinavian countries, headed by Denmark, register the highest scores. This performance could be explained by the fact that their government is subject to systematic control from citizens (information on public authorities activities is available to all citizens). In addition, the reduced level of corruption determines citizens to have confidence in government, paying higher taxes than anywhere else in EU. Scandinavian countries also registered the highest level of public investments and large social protection expenditures in 2015.

The employment rate was also important in the index development, varying from $80.5 \%$ in Sweden to $54.9 \%$ in Greece. This major difference explains the issues on integrating EU citizens into the labor market. Greece, Spain, and Croatia, with low employment rates, also indicate a low confidence on public institutions and government. This is strongly affecting life satisfaction, as these countries have the least citizens to evaluate their quality of life with "high".

From this paper, we can conclude that there are important differences in terms of economic and social development in the EU. The variance is due to economic shocks, or to government transparency and corruption. All these are affecting citizens happiness and their confidence in public institutions. Therefore, a big problem in many countries may be the failure of political parties and the lack of credible institutions.

For the EU to have success in promoting and implementing policies across member states, in order to gain the citizens confidence, governmental reforms are needed, in order to ensure the public institutions transparency and limit the corruption. As the Scandinavian model is the most efficient, countries can implement similar policies in order to return to a sustainable growth path.

\section{REFERENCES}

Collier, P. (2007). The Bottom Billion. Why the Poorest Countries are Failing and What Can Be Done About It. Oxford University Press, New York. Retrieved January 20, 2018, from https://www. sfu.ca/content/sfu/dean-gradstudies/events/dreamcolloquium/ SpringColloquium/Readings/ Readings/_jcr_content/main_content/download_47/file.res/Paul\%20Collier.

European Commission (2018). European Quality of Government Index 2017. Retrieved February 24, 2018, from http://ec.europa.eu/regional_policy/en/information/maps/ quality_of_governance.

Kaufmann, D., Kraay, A. \& Mastruzzi, M. (2009). Governance Matters VIII: Aggregate and Individual Governance Indicators 1996-2008. Policy Research working paper World Bank, no. WPS 4978. Retrieved January 20, 2018, from https://openknowledge.worldbank.org/handle/10986/4170.

Rothstein, B. \& Teorell, J. (2008). What is Quality of Government? A Theory of Impartial Government Institutions. Governance, 21(2), 165-190. DOI: 10.1111/j.1468-0491.2008.00391.x. 